\title{
DEFENSE RESPONSE TRIGGERED BY SCLEROTIUM ROLFSII IN TEA PLANTS
}

\author{
Indramani Bhagat ${ }^{1}$ and Bishwanath Chakraborty ${ }^{2}$ \\ ${ }^{1}$ Department of Botany, Post Graduate Campus, Biratnagar, Nepal \\ ${ }^{2}$ Immuno-Phytopathology Laboratory, University of North Bengal, Siliguri-734013, West Bengal, India \\ *E-mail: drskbhagat04@yahoo.com
}

\begin{abstract}
Total phenols and ortho-dihydroxy phenols from healthy and Sclerotium.rolfsii inoculated roots of 18 varieties of tea [Camellia sinensis (L.) O. Kuntze] were estimated after 7 days of inoculation. The total phenol contents and ortho-dihydroxy phenols decreased in susceptible varieties and increased in resistant varieties following inoculation with S. rolfsii. Among all the tested varieties, K-1/1 variety showed maximum increase in total phenols and ortho-dihydroxy phenol contents after inoculation with S. rolfsii. Phenylalanine ammonia lyase (PAL) activity was increased after 4 days of inoculation in eighteen tested varieties. Highest increase in PAL activity was seen on tea roots of TV-26 variety. Peroxidase activity was also increased in all the tested varieties and highest increase was noticed in HV-39 variety. The results showed that changes in the levels of phenols and the enzymes like PAL and Peroxidase (POD) form an important part in the resistance mechanism of the tea plants against infections with S. rolfsii. Resistant varities of tea plants might have an inducible system to produce phenolic compounds and activate certain enzymes following infection with the pathogen whereas susceptible varities seem to be suppressive in this aspect.
\end{abstract}

Key words: Resting pathogen, resistance mechanism.

\section{INTRODUCTION}

Sclerotial blight caused by Sclerotium rolfsii Sacc. [telomorph: Athelia rolfsii (Curzi), Tu and Kimbrough $=$ Corticium rolfsii $($ Curzi) $]$ is one of the fungal diseases which appears in the nursery grown seedlings of tea. The fungus is a soil borne rotting pathogen of very aggressive nature and causes considerable damage to young tea seedlings in the nursery, which is very common in the plains but rare in the hills. Sclerotium rolfsii is a wide spread pathogen that affects at least 500 species belonging to 100 plant families. The interaction between plants and their pathogens is complex and may be very specific to a given combination of the plant and the fungus.

Resistance in plants towards pathogens depends on various factors. Several authors have demonstrated a distinct correlation between the degree of plant resistance and phenolics present in plant tissues (Sridhar and Ou 1974, Hammerschmidt and Nicholson 1977). Phenylalanine ammonia lyase (PAL) and 
peroxidase (POD) are two oxidative enzymes which are frequently involved in biosynthetic processes associated with infection by phytopathogens (Southerton and Deverall 1990). As polyphenols are the major constituents of tea roots, it was decided to compare quantitative changes in the phenolics and defense enzymes of resistant and susceptible varieties.

\section{MATERIALS AND METHODS}

\section{Plant material}

Eighteen varieties of tea which includes five Tocklai varieties (TV-18, TV-22, TV-25, TV-26 and TV-30), six UPASI varieties (UP-2, UP-3, UP-8, UP-9, UP-26 and BSS-2) and seven Darjeeling varieties (Teen Ali -17/1/54, AV-2, HV-39, T-78, T-135, K-1/1 and B-157) maintained in Tea Germplasm Bank at the Department of Botany, North Bengal University were used for experimental purposes. These were originally collected from Tocklai Experimental Station, Jorhat, Assam, UPASI Tea Research Station, Valparai, Tamilnadu and Darjeeling Tea Research Centre, Kurseong, Darjeeling, respectively.

\section{Fungal culture}

Virulent culture of $S$. rolfsii Sacc was obtained from Immuno-Phytopathology Laboratory, Department of Botany, North Bengal University. This was originally isolated from Teen Ali-17/1/54 and after completion of Koch's postulate, the organism was identified by the Global Plant Clinic, Diagnostic and Advisory Service, CABI Bioscience UK and designated as Sr-1.

\section{Preparation of inoculum and inoculation technique}

Fungal pathogen $S$. rolfsii was cultured on PDA medium. After 14 days, brown colored sclerotia of S. rolfsii were formed. A small portion of fungal mycelia with sclerotia were taken and incubated at
$28^{0} \mathrm{C}$ for 7 days. The inoculum was mixed with sterile soil at the ratio of 1:8. Fungus soil mixture $(100 \mathrm{~g})$ were mixed with the top soil of earthen pots containing tea seedlings and kept for development of disease reaction.

One-year tea seedlings were planted in earthen pots containing $1 \mathrm{~kg}$ soil and allowed to be established. Regular watering was done for two weeks and then $100 \mathrm{~g}$ of pathogen inoculum was added carefully in the rhizosphere of each plant. Disease assessment was done by observing the external symptoms thrice (15, 30 and 45 days) after inoculation. Disease intensity was assessed on the basis of above ground and underground symptoms together on a scale of 0-6, 0-no disease; 1 -small roots turn rotten; 2-leaves start wilting and $10-20 \%$ of the roots turn brown; 3-leaves wilted and $20-40 \%$ roots become dry with browning of shoots; 4-extensive rotting at the collar region of root $60-70 \%$ of the roots and leaves wilted, browning of shoot over $60 \% ; 5-80 \%$ roots affected while the root along with the leaves withered and shoot becomes brown more than $80 \%$; 6-whole plants die.

\section{Extraction and estimation of phenolics}

Phenols were extracted and assayed as described by Mahadevan and Sridhar (1982), with modification. Tea root tissue (1 g) was cut into small pieces and immediately immersed in boiling absolute alcohol which was then boiled on a boiling water bath for 5-10 min, using $4 \mathrm{ml}$ of alcohol/1 $\mathrm{g}$ of tissue. After cooling, the tissues were crushed with mortar and pestle using $80 \%$ alcohol and were filtered. Residues were reextracted as before boiling for $3 \mathrm{~min}$ and filtered. Both the filtrates were mixed and final volume (4 $\mathrm{ml}$ ) was made up with $80 \%$ alcohol. Extracts were stored at $4^{0} \mathrm{C}$ in separate vials, covered with brown paper. The whole extraction was done in dark to prevent light induced degradation of phenol. 
Total phenol was estimated by FolinCiocalteau's method as described by Mahadevan and Ulaganathan (1991). To $1 \mathrm{ml}$ of phenolic extract, $1 \mathrm{ml}$ of Folin-Ciocalteau's reagent and 2 $\mathrm{ml}$ of $20 \% \mathrm{Na}_{2} \mathrm{CO}_{3}$ were added, shaken properly and heated on a boiling water bath for $1 \mathrm{~min}$. Finally, the volume was adjusted to $25 \mathrm{ml}$ with double distilled water. Absorbance was measured in a Systronics photoelectric colorimeter Model101 at $650 \mathrm{~nm}$. Quantity of total phenol was estimated using caffeic acid as standard.

Ortho-dihydroxy phenol was estimated as described by Mahadevan and Ulaganathan (1991). In $1 \mathrm{ml}$ of each phenolic extract, $2 \mathrm{ml}$ of $0.5(\mathrm{~N})$ $\mathrm{HCl}, 1 \mathrm{ml}$ Arnow's reagent $\left(\mathrm{NaNO}_{3}-10 \mathrm{~g}\right.$; $\mathrm{Na}_{2} \mathrm{MoO}_{4}-10 \mathrm{~g}$; distilled water $100 \mathrm{ml}$ ) and $2 \mathrm{ml}$ of $1(\mathrm{~N}) \mathrm{NaOH}$ were added. These were then adjusted to $10 \mathrm{ml}$ diluting with double distilled water. The tubes were shaken well and absorbance was recorded by Systronics photoelectric colorimeter Model-101 at $515 \mathrm{~nm}$. Quantity of ortho-dihydroxy phenol was estimated using caffeic acid as standard.

\section{Extraction and assay of Phenylalanine ammonia lyase}

For the extraction of phenylalanine ammonia lyase, the method of Bhattacharya and Ward (1987) was followed with some modifications. Tea root tissue ( $1 \mathrm{~g}$ ) was crushed in a mortar with pestle in $5 \mathrm{ml}$ of $0.1 \mathrm{M}$ sodium borate buffer $(\mathrm{pH}$ 8.8) containing $2 \mathrm{mM} \beta$-mercaptoethanol in ice. The crushed material was centrifuged at 12,000 rpm for $20 \mathrm{~min}$ at $4^{0} \mathrm{C}$. The supernatant was collected, volume recorded and then immediately used for assay. PAL activity in the supernatant was determined by measuring the production of cinnamic acid from L-phenylalanine spectrophotometrically. The reaction mixture (total volume $3 \mathrm{ml}$ ) contained $0.3 \mathrm{ml} 300 \mu \mathrm{M}$ sodium borate ( $\mathrm{pH} 8.8$ ), $0.3 \mathrm{ml} 0.3 \square \mu \mathrm{M}$ L-phenylalanine and $0.5 \mathrm{ml}$ of enzyme extract and $1.9 \mathrm{ml}$ of double distilled water. Blank was prepared in the same way but with water instead of enzyme extract. Then the tubes were incubated at $37^{\circ} \mathrm{C}$ for $1 \mathrm{~h}$ in water bath. After $1 \mathrm{~h}$ absorbance was noted at 295 $\mathrm{nm}$ in UV-VIS-spectrophotometer (SICO, Digispec - 200 GL) against a blank without the enzyme in the assay mixture. The enzyme activity was expressed as $\mu \mathrm{g}$ cinnamic acid/min.

\section{Extraction and assay of Peroxidase}

To extract peroxidase, the method of Chakraborty et al. (1993) was followed with modification. Tea root tissue (1 g) was crushed with $0.1 \mathrm{M}$ sodium borate buffer $(\mathrm{pH}$ 8.8) containing $2 \mathrm{mM} \beta$-mercaptoethanol in mortar with pestle on ice. The crushed material was centrifuged at $12,000 \mathrm{rpm}$ for $20 \mathrm{~min}$ at $4^{0} \mathrm{C}$. The supernatant was collected and its final volume was measured and used immediately for assay. For the assay of POD activity, $100 \square \mu$ l of freshly prepared crude enzyme was added to the reaction mixture containing $1 \mathrm{ml}$ of 0.2 (M) sodium phosphate

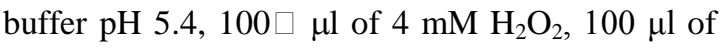
orthodianisidine $(5 \mathrm{mg} / \mathrm{ml}$ methanol) and $1.7 \mathrm{ml}$ of double distilled water. POD activity was assayed spectrophotometrically at $495 \mathrm{~nm}$ by monitoring the oxidatioin of o-dianisidine in the presence of $\mathrm{H}_{2} \mathrm{O}_{2}$. Specific activity was expressed as the increase in absorbance at $495 \mathrm{~nm} / \mathrm{g}$ tissue $/ \mathrm{min}$.

\section{RESULTS}

Total phenols from healthy and $S$. rolfsii inoculated roots of 18 tea varieties were extracted after 7 days of inoculation and estimated. Results (Table 1) showed a decrease in total phenol content following inoculation with $S$. rolfsii in the susceptible varieties, whereas there was an increase in the phenol content of resistant varieties. Among all the varieties tested, K-1/1 showed maximum increase in total phenol following inoculation with S. rolfsii. 
Table 1. Total phenol content in healthy and Sclerotium rolfsii inoculated tea roots.

\begin{tabular}{|c|c|c|}
\hline \multirow{2}{*}{ Tea Varieties } & \multicolumn{2}{|c|}{ Total phenol (mg/g tissue $)^{a}$} \\
\hline & Healthy & Inoculated $^{b}$ \\
\hline \multicolumn{3}{|l|}{ Susceptible } \\
\hline $\mathrm{T}-17$ & $6.5 \pm 0.05$ & $4.5 \pm 0.04$ \\
\hline TV-18 & $4.7 \pm 0.02$ & $4.1 \pm 0.03$ \\
\hline TV -22 & $5.1 \pm 0.01$ & $4.8 \pm 0.02$ \\
\hline TV -25 & $3.5 \pm 0.04$ & $2.1 \pm 0.03$ \\
\hline TV-30 & $4.7 \pm 0.01$ & $4.5 \pm 0.03$ \\
\hline UP-3 & $4.4 \pm 0.04$ & $2.4 \pm 0.01$ \\
\hline UP-8 & $3.1 \pm 0.05$ & $2.8 \pm 0.03$ \\
\hline UP-9 & $5.1 \pm 0.02$ & $3.6 \pm 0.01$ \\
\hline UP-26 & $4.8 \pm 0.03$ & $2.9 \pm 0.02$ \\
\hline B-157 & $4.6 \pm 0.06$ & $3.5 \pm 0.04$ \\
\hline $\mathrm{AV}-2$ & $4.3 \pm 0.02$ & $3.2 \pm 0.01$ \\
\hline $\mathrm{T}-78$ & $4.7 \pm 0.03$ & $4.1 \pm 0.02$ \\
\hline $\mathrm{T}-135$ & $3.6 \pm 0.02$ & $3.3 \pm 0.01$ \\
\hline \multicolumn{3}{|l|}{ Resistant } \\
\hline UP-2 & $5.1 \pm 0.03$ & $5.8 \pm 0.01$ \\
\hline TV-26 & $3.6 \pm 0.04$ & $5.1 \pm 0.02$ \\
\hline BSS-2 & $3.5 \pm 0.03$ & $6.6 \pm 0.01$ \\
\hline $\mathrm{K}-1 / 1$ & $2.9 \pm 0.02$ & $7.0 \pm 0.01$ \\
\hline HV-39 & $3.4 \pm 0.03$ & $3.6 \pm 0.02$ \\
\hline
\end{tabular}

${ }^{\text {a }}$ Average of three replicates, \pm standard error

b 7 days following inoculation with $S$. rolfsii

Similarly, results (Table 2) revealed that orthodihydroxy phenol content decreased in susceptible varieties (T-17, TV-18, TV-22, TV-25, TV-30, UP-3, UP-8, UP-26, B-157, AV-2, T-78 and T135) and increased in resistant varieties (UP-2, TV-26, BSS-2, K-1/1 and HV-39). Among 5 tested resistant varieties, tea roots of $\mathrm{K}-1 / 1$, followed by TV-26 and BSS-2 showed maximum increase in orthodihydroxy phenol content after inoculation with $S$. rolfsii.
Table 2. Level of Ortho-dihydroxy phenol in healthy and Sclerotium rolfsii inoculated tea roots.

\begin{tabular}{|c|c|c|}
\hline \multirow[t]{2}{*}{ Tea Varieties } & \multicolumn{2}{|c|}{$\begin{array}{l}\text { Ortho-dihydroxy phenol } \\
\quad(\mathrm{mg} / \mathrm{g} \text { root tissue })^{\mathrm{a}}\end{array}$} \\
\hline & Healthy & Inoculated $^{b}$ \\
\hline \multicolumn{3}{|l|}{ Susceptible } \\
\hline $\mathrm{T}-17$ & $2.1 \pm 0.03$ & $1.2 \pm 0.02$ \\
\hline TV-18 & $1.6 \pm 0.04$ & $1.5 \pm 0.01$ \\
\hline TV-22 & $2.7 \pm 0.03$ & $2.1 \pm 0.02$ \\
\hline TV -25 & $1.08 \pm 0.02$ & $0.4 \pm 0.01$ \\
\hline TV -30 & $2.1 \pm 0.03$ & $1.1 \pm 0.02$ \\
\hline UP-3 & $2.5 \pm 0.02$ & $1.5 \pm 0.01$ \\
\hline UP-8 & $1.4 \pm 0.03$ & $1.2 \pm 0.01$ \\
\hline UP-9 & $2.1 \pm 0.02$ & $1.7 \pm 0.01$ \\
\hline UP-26 & $2.3 \pm 0.03$ & $1.4 \pm 0.02$ \\
\hline B-157 & $1.9 \pm 0.02$ & $0.6 \pm 0.03$ \\
\hline AV-2 & $1.8 \pm 0.04$ & $1.3 \pm 0.03$ \\
\hline $\mathrm{T}-78$ & $1.7 \pm 0.02$ & $1.6 \pm 0.01$ \\
\hline $\mathrm{T}-135$ & $1.4 \pm 0.03$ & $1.3 \pm 0.01$ \\
\hline \multicolumn{3}{|l|}{ Resistant } \\
\hline UP-2 & $1.3 \pm 0.04$ & $2.3 \pm 0.03$ \\
\hline TV-26 & $1.2 \pm 0.05$ & $2.3 \pm 0.04$ \\
\hline BSS-2 & $1.7 \pm 0.03$ & $2.8 \pm 0.02$ \\
\hline $\mathrm{K}-1 / 1$ & $0.9 \pm 0.04$ & $2.3 \pm 0.01$ \\
\hline HV-39 & $1.3 \pm 0.03$ & $1.4 \pm 0.02$ \\
\hline
\end{tabular}

${ }^{a}$ Average of three replicates, \pm standard error

b 7 days following inoculation with $S$. rolfsii

PAL is the first enzyme of phenyl propanoid metabolism in higher plants and it has been suggested to play a significant role in regulating the accumulation of phenolics, phytoalexins and lignins, three key factors responsible for disease resistance. PAL activity was assayed in each case after 2, 4 and 8 days after inoculation. Results (Table 3) showed that PAL activity increased after 4 days of inoculation in TV-18, TV-25, TV-30, UP-26, AV-2, T-78, T-135, UP-2, BSS-2, K-1/1 and HV-39 markedly. The highest PAL activity was observed in tea roots of TV 25 after inoculation with $S$. rolfsii. 
Table 3. Changes in phenylalanine ammonia lyase activity in tea roots following inoculation with Sclerotium rolfsii.

\begin{tabular}{|c|c|c|c|c|c|c|}
\hline \multirow{3}{*}{$\begin{array}{l}\text { Tea } \\
\text { Varieties }\end{array}$} & \multicolumn{6}{|c|}{ PAL activity in tea roots $\left(\Delta \mathrm{g} \text { cinnamic acid } \mathrm{g}^{-1} \mathrm{~m}^{-1}\right)^{\mathrm{a}}$} \\
\hline & \multicolumn{2}{|c|}{2} & \multicolumn{2}{|c|}{4} & \multicolumn{2}{|c|}{8} \\
\hline & Healthy & Infected & Healthy & Infected & Healthy & Infected \\
\hline BSS-2 & $144.3 \pm 1.54$ & $90.8 \pm 0.96$ & $136.6 \pm 0.63$ & $151.5 \pm 0.81$ & $132.6 \pm 0.49$ & $42.1 \pm 1.24$ \\
\hline UP-2 & $107.9 \pm 0.26$ & $72.6 \pm 0.66$ & $31.6 \pm 0.26$ & $249.1 \pm 2.13$ & $105.9 \pm 0.47$ & $35.3 \pm 0.84$ \\
\hline UP-3 & $117.1 \pm 0.53$ & $101.7 \pm 0.32$ & $127.8 \pm 1.17$ & $111.94 \pm 0.31$ & $121.67 \pm 1.04$ & $55.6 \pm 0.49$ \\
\hline UP-8 & $84.08 \pm 0.62$ & $70.4 \pm 0.52$ & $89.5 \pm 0.47$ & $144.8 \pm 0.59$ & $92.2 \pm 2.20$ & $56.4 \pm 0.37$ \\
\hline UP-9 & $56.08 \pm 0.42$ & $30.7 \pm 0.62$ & $58.9 \pm 0.32$ & $92.1 \pm 0.23$ & $55.2 \pm 0.85$ & $29.5 \pm 0.77$ \\
\hline UP-26 & $165.3 \pm 1.02$ & $74.3 \pm 1.31$ & $155.06 \pm 0.47$ & $148.9 \pm 0.49$ & $159.9 \pm 0.51$ & $27.7 \pm 0.9$ \\
\hline TV-18 & $164.6 \pm 1.17$ & $37.01 \pm 0.58$ & $167.2 \pm 0.70$ & $175.06 \pm 1.77$ & $162.3 \pm 0.47$ & $140.5 \pm 1.89$ \\
\hline TV-22 & $89.2 \pm 0.81$ & $22.7 \pm 0.39$ & $32 \pm 0.40$ & $150.5 \pm 0.40$ & $94.9 \pm 0.44$ & $77.1 \pm 0.79$ \\
\hline TV -25 & $87 \pm 0.53$ & $156.03 \pm 0.38$ & $84.2 \pm 0.75$ & $165.4 \pm 0.32$ & $81.2 \pm 0.86$ & $130.07 \pm 0.09$ \\
\hline TV-26 & $72.7 \pm 1.51$ & $58 \pm 0.40$ & $76.1 \pm 1.31$ & $175.9 \pm 0.53$ & $81.9 \pm 1.24$ & $98.6 \pm 0.98$ \\
\hline $\mathrm{T}-17$ & $64.9 \pm 0.28$ & $74.8 \pm 0.47$ & $116.8 \pm 0.47$ & $131.2 \pm 0.95$ & $121.8 \pm 0.47$ & $90.3 \pm 0.81$ \\
\hline TV-30 & $95 \pm 1.98$ & $28.0 \pm 0.57$ & $92.27 \pm 0.65$ & $135.8 \pm 0.54$ & $90.6 \pm 0.42$ & $52 \pm 0.57$ \\
\hline $\mathrm{T}-78$ & $91.6 \pm 0.48$ & $49.6 \pm 0.54$ & $94.7 \pm 1.03$ & $165.2 \pm 0.38$ & $89.7 \pm 0.32$ & $143.2 \pm 0.14$ \\
\hline $\mathrm{AV}-2$ & $33.7 \pm 0.44$ & $78.8 \pm 0.5$ & $43.8 \pm 0.37$ & $128.8 \pm 0.59$ & $45.9 \pm 0.98$ & $100.8 \pm 0.29$ \\
\hline $\mathrm{T}-135$ & $108.8 \pm 0.65$ & $68.06 \pm 0.75$ & $91.7 \pm 0.64$ & $296.2 \pm 0.53$ & $96.2 \pm 0.65$ & $103.9 \pm 0.37$ \\
\hline B157 & $73.6 \pm 0.59$ & $91.4 \pm 0.94$ & $74.2 \pm 1.14$ & $136.6 \pm 0.32$ & $77.5 \pm 0.56$ & $111.4 \pm 0.28$ \\
\hline HV-39 & $132.6 \pm 0.49$ & $170.7 \pm 0.62$ & $84.3 \pm 0.94$ & $178.8 \pm 0.51$ & $135.1 \pm 0.83$ & $64.8 \pm 0.12$ \\
\hline $\mathrm{K}-1 / 1$ & $133.06 \pm 0.47$ & $165.2 \pm 0.57$ & $135.9 \pm 0.53$ & $234.06 \pm 0.41$ & $142.9 \pm 0.94$ & $65.9 \pm 0.5$ \\
\hline
\end{tabular}

${ }^{\text {a }}$ Average of 3 replicates, \pm Standard error

Table 4. Changes in peroxidase activity in tea roots following inoculation with Sclerotium rolfsii.

\begin{tabular}{|c|c|c|c|c|c|c|}
\hline \multirow{3}{*}{$\begin{array}{l}\text { Tea } \\
\text { Varieties }\end{array}$} & \multicolumn{6}{|c|}{$P O D$ activity in tea roots $(\Delta O D / g \text { tissue } / \mathrm{min})^{\mathrm{a}}$} \\
\hline & \multicolumn{2}{|c|}{2} & \multicolumn{2}{|c|}{4} & \multicolumn{2}{|c|}{8} \\
\hline & Healthy & Infected & Healthy & Infected & Healthy & Infected \\
\hline BSS-2 & $0.93 \pm 0.02$ & $0.74 \pm 0.02$ & $0.87 \pm 0.01$ & $1.31 \pm 0.01$ & $0.94 \pm 0.03$ & $0.96 \pm 0.02$ \\
\hline UP-2 & $0.66 \pm 0.03$ & $0.89 \pm 0.07$ & $0.55 \pm 0.12$ & $1.23 \pm 0.04$ & $0.68 \pm 0.02$ & $0.92 \pm 0.02$ \\
\hline UP-3 & $0.54 \pm 0.12$ & $0.75 \pm 0.11$ & $0.655 \pm 0.12$ & $1.26 \pm 0.06$ & $0.55 \pm 0.12$ & $0.76 \pm 0.03$ \\
\hline UP-8 & $0.63 \pm 0.04$ & $1.2 \pm 0.08$ & $0.66 \pm 0.12$ & $1.66 \pm 0.12$ & $0.73 \pm 0.13$ & $1.27 \pm 0.44$ \\
\hline UP-9 & $0.9 \pm 0.8$ & $1.03 \pm 0.12$ & $1.03 \pm 0.12$ & $1.2 \pm 0.07$ & $1.16 \pm 0.12$ & $1.1 \pm 0.16$ \\
\hline UP-26 & $0.77 \pm 0.13$ & $0.87 \pm 0.04$ & $0.87 \pm 0.12$ & $1.6 \pm 0.08$ & $0.83 \pm 0.07$ & $0.87 \pm 0.01$ \\
\hline TV-18 & $1.57 \pm 0.17$ & $1.12 \pm 0.05$ & $1.67 \pm 0.2$ & $1.76 \pm 0.12$ & $1.5 \pm 0.08$ & $1.14 \pm 0.02$ \\
\hline TV-22 & $0.67 \pm 0.12$ & $0.17 \pm 0.01$ & $0.68 \pm 0.16$ & $1.82 \pm 0.09$ & $0.66 \pm 0.12$ & $1.17 \pm 0.2$ \\
\hline TV-25 & $1.13 \pm 0.01$ & $1.17 \pm 0.01$ & $1.12 \pm 0.05$ & $1.31 \pm 0.08$ & $1.16 \pm 0.02$ & $1.18 \pm 0.02$ \\
\hline
\end{tabular}




\begin{tabular}{lcccccc} 
TV-26 & $1.6 \pm 0.12$ & $1.73 \pm 0.12$ & $1.3 \pm 0.07$ & $1.89 \pm 0.03$ & $0.91 \pm 0.08$ & $1.76 \pm 0.06$ \\
T-17 & $0.81 \pm 0.06$ & $1.11 \pm 0.06$ & $1.1 \pm 0.35$ & $1.71 \pm 0.08$ & $1.31 \pm 0.08$ & $1.4 \pm 0.04$ \\
TV-30 & $1.03 \pm 0.01$ & $1.07 \pm 0.02$ & $1.07 \pm 0.01$ & $1.36 \pm 0.12$ & $1.04 \pm 0.02$ & $1.08 \pm 0.01$ \\
T-78 & $1.23 \pm 0.2$ & $1.72 \pm 0.17$ & $1.08 \pm 0.02$ & $1.91 \pm 0.02$ & $1.06 \pm 0.02$ & $1.76 \pm 0.03$ \\
AV-2 & $0.21 \pm 0.08$ & $0.83 \pm 0.05$ & $0.3 \pm 0.16$ & $0.93 \pm 0.04$ & $0.23 \pm 0.12$ & $0.84 \pm 0.01$ \\
T-135 & $0.69 \pm 0.16$ & $1.29 \pm 0.08$ & $0.76 \pm 0.12$ & $1.1 \pm 0.49$ & $1.42 \pm 0.09$ & $1.09 \pm 0.08$ \\
B157 & $1.16 \pm 0.02$ & $1.33 \pm 0.16$ & $1.11 \pm 0.07$ & $1.46 \pm 0.3$ & $1.14 \pm 0.1$ & $1.16 \pm 0.01$ \\
HV-39 & $0.63 \pm 0.12$ & $1.63 \pm 0.12$ & $0.86 \pm 0.04$ & $3.06 \pm 1.44$ & $0.86 \pm 0.04$ & $01.85 \pm 0.07$ \\
K-1/1 & $1.06 \pm 0.3$ & $1.06 \pm 0.3$ & $1.03 \pm 0.41$ & $2.4 \pm 0.08$ & $1.04 \pm 0.02$ & $1.47 \pm 0.02$ \\
\hline
\end{tabular}

${ }^{\mathrm{a}}$ Average of 3 replicates, ${ }^{\mathrm{b}}$ Days after inoculation, \pm Standard error

POD causes o-dianisidine to react with $\mathrm{H}_{2} \mathrm{O}_{2}$ to form-oxidized o-dianisidine, the absorbance of which is assayed. The rate of absorbance is the measure of the POD activity. Peroxidase was extracted from healthy and $S$. rolfsii inoculated tea roots of 18 varieties and their activity was assayed after 2, 4 and 8 days of inoculation. Peroxidase activity was also increased in all tested varieties and highest increase was noticed in HV-39 after 4 days of inoculation (Table 4).

\section{DISCUSSION}

In the present study, total phenol content decreased with pathogen infection in susceptible varieties of tea but increased in resistant varieties. Since Phenylalanine ammonia lyase is a defense enzyme so it increased in both susceptible and resistance varieties. However, in the susceptible varieties PAL activity increased significantly.

Alteration of phenol metabolism following fungal infection has been observed in many diseases and phenolics have been implicated in the defense reaction in several instances (Mahadevan 1991). Biochemical responses to tea plants exposed to biotic stress due to blister blight infection caused by Exobasidium vexans in the levels of phenols and enzyme activities were studied (Chakraborty et al. 2002, Sharma and Chakraborty 2004).

ECOPRINT VOL 17, 2010
In the present study, the levels of phenolics in roots of resistant and susceptible tea varieties were estimated following inoculation with $S$. rolfsii. Host responses could be differentiated by changes in content of phenolic compounds. In both the cases total phenol and orthodihydroxy phenol content increased in resistant varieties but decreased in susceptible varieties in comparison to their healthy controls. Hammerschmidt and Nicholson (1977) demostrated a clear difference between resistant and susceptible interaction of maize to Colletotrichum graminicola based on accumulation of phenols. Sridhar and Ou (1974) also reported differences in total phenolics accumulation in the interaction of Pyricularia oryzae with rice. In the present study, there was a greater accumulation of Orthodihydroxy phenol in resistant varieties. It is due to interaction of $S$. rolfsii and tea varieties. It indicated that this might play a role in disease resistance mechanism.

Accumulation of defense enzymes such as phenylalanine ammonia lyase (PAL), polyphenol oxidase (PPO), peroxidase (POD), in tea varieties following inoculation with $S$. rolfsii were determined. Increased activity of PPO and PO was demonstrated in the cucumber leaf in the vicinity of the lesions caused by some foliar pathogens or by phosphate application (Avdiushko et al. 1993). Among all the stress related enzymes, the role of 
peroxidase has been most thoroughly worked out. POD is a metallo-enzyme containing porphyrin bound iron. The enzyme acts on a wide range of substrates including phenols, aromatic amines, amino acids and inorganic compounds (Balasimaha 1982). These are ubiquitous to plants and are characterized by a large number of isozymes. Various naturally occurring and synthetic substances, growth regulator and environmental factors markedly influence the activity of these peroxidases. Akhtar and Garraway (1990) observed increased POD activity in susceptible cultivars compared with the resistant one when both were treated with sodium bisulphate prior to inoculation with Botrytis maydis. On the other hand there are also reports of increased POD activity due to induction of resistance (Chen et al. 2000). The existence of multiple molecular forms of peroxidase in tea has also been reported (Sharma and Chakraborty 2004).

Previous reports indicate that oxidative enzymes such as PPO and PO as well as those involved in phenolic biosynthesis such as PAL are involved in defense reactions in plants (Chen et al. 2000). Considering the importance of phenol metabolism in tea plants, those three enzymes were selected for studies. Results showed that the constitutive enzyme activities under no stress conditions of the different tea seelings varied. An elevation in the level of activity of PAL has been frequently demonstrated to be one of the earliest responses of plants to biotic (Chakraborty et al. 1993, Shiraishi et al. 1995) or to other environmental stresses (Eckey-Kaltenbach et al. 1997). It was reported by Orczyk et al. (1996) in sorghum, naturally occurring high levels of PAL activity induced by light should be differentiated from the activity induced as a response of attempted fungal infection. Bhattacharya and Ward (1987) reported that PAL activity in soybean was enhanced in the resistance response of soybean hypocotyls to Phytophthora megasperma f. sp. glycinea.

\section{ACKNOWLEDGEMENTS}

Financial assistance received by Indramani Bhagat from University Grants Commission, Nepal to conduct the present investigation at ImmunoPhytopathology Laboratory, Department of Botany, North Bengal University, India is gratefully acknowledged.

\section{REFERENCES}

Akhtar, M. and M.O. Gurraway. 1990. Effect of sodium bisulphate in peroxidase activity and electrolyte leakage in maize in relation to sporulation of Bipolaris maydis race. Ohio. J. Sci. 3:71-76.

Avdiushko, S.A., X.S. Ye and J. Kuc. 1993. Detection of several enzymatic activities in leaf prints cucumber plants. Physiol. Mol. Plant Pathol. 42:441-454.

Balasimha, D. 1982. Regulation of peroxidases in higher plants - A review. Plant Physiology. Biochem. 9:130-143.

Bhattacharya, M.K. and E.W.B. Ward. 1987. Temperature induced susceptibility of soybeans to Phytophthora megasperma f. sp. glycinea; phenylalanine ammomia lyase and glyceollin sensitivity of the pathogen. Physiol. Mol. Plant Pathol. 31:407-419.

Chakraborty, B.N., S. Datta and U. Chakraborty. 2002. Biochemical responses of tea plants induced by foliar infection with Exobasidium vexans. Indian Phytopath. 55(1):8-13.

Chakraborty, U., B.N. Chakraborty and M. Kapoor. 1993. Changes in the levels of peroxidase and phenylalanine ammonia - lyase in Brassica napus cultivars showing variable resistance to Leptosphaeria maculans. Folia Microbiol. 38:491-496. 
Chen, C., R.R. Be'langer, N. Benhamou and T. Pautitz. 2000. Defense enzyme induced in cucumber roots by treatment with plant growth promoting rhizobacteria (PGPR) and Pythium aphanidermatum. Physiol. Mol. Plant Pathol. 56: $13-23$

Eckey-Kaltenbach, H., E. Kiefer, E. Grosskopf, D. Ernst and H. Sandermann. 1997. Differential transcript induction of parsely pathogenesis related proteins and of a small heat shock protein by ozone and heat shock. Plant Mol. Biol. 33:343-350.

Hammerschmidt, R. and R.L. Nicholson. 1977. Resistance of maize to anthracnose: Change in host phenols and pigments. Phytopathology 67:251-258.

Mahadevan, A. 1991. Biochemical aspects of plant disease resistance. In: Post-Infectional Defence Mechanisms. Today and Tomorrow's Printers and Publishers, New Delhi, pp. 871.

Mahadevan, A. and R. Sridhar, R. 1982. Methods in Physiological Plant Pathology ( $2^{\text {nd }}$ Edn). Sivakami Publication, Madras, India.

Mahadevan, A. and K. Ulaganathan. 1991. Techniques Molecular in Plant Pathology Sivakami Publication. Madras, India, pp. 219.
Orczyk, W., J. Hipskind, E. De. Neergaard, P. Goldsbrough and R.L. Nicholson. 1996. Stimulation of phenylalnine ammonia lyase in sorghum in response to inoculation with Bipolaris maydis. Physiol. Mol. Plant Pathol. 48:55-69.

Sharma, M. and B.N. Chakraborty. 2004. Biochemical and immunological characterization of defense related proteins of tea plants triggered by Exobasidium vexans. Massee. J. Mycol. Pl. Pathol. 34(3):742-760.

Shiraishi, T., T. Yamada, R.L. Nicholson and A. Kunoll. 1995. Phenylalanine ammonia lyase in barley activity enhancement in response to Erysiphe pisi, a nonpathogen. Physiol. Mol. Plant Pathol. 46:153-162.

Sridhar, R. and S.H. Ou. 1974. Phenolic compounds detected in rice blast disease. Biol. Plant 16:67-70.

Southerton, S.G. and B.J. Deverall. 1990. Changes in phenylalanine ammonia-lyase and peroxidase activities in wheat cultivars expressing resistance to the leaf -rust fungus. Plant Pathol. 39:223-23 